\title{
The ruling relations of patient involvement in cardiac rehabilitation programs
}

\author{
Nynne Barchager \\ Department of People and Technology, Roskilde University, Roskilde, Denmark
}

\begin{abstract}
Patient involvement has often been defined and examined on the basis of conceptual theoretical frameworks. This article explores patient involvement contextually and locally, in encounters between patients and healthcare professionals in cardiac rehabilitation in Denmark. With inspiration from institutional ethnography, the goal is to unpack what involvement actually implies in rehabilitation activities. The analysis provides micro-sociological insights into how patient involvement is constituted and institutionally conditioned and shows how textually mediated ruling relations regulate activities and interactions, shaping patient involvement in local practices. The analysis reveals how patient involvement primarily relates to

Nynne Barchager, Department of People and Technology, Roskilde University, Universitetsvej 1, Building 44.1, 4000 Roskilde, Denmark.

E-mail: nyba@ruc.dk

Key words: Patient involvement; institutional ethnography; cardiac rehabilitation; clinical guidelines.

Acknowledgements: A big thank you to the healthcare profession-

healthcare professionals involving patients in health knowledge. It explores how national guidelines and local instructions for healthcare professionals frame understandings of patient needs and problems. The concluding discussion highlights how patients have limited opportunities to influence their own care process. It also points out how it is left to the individual healthcare professional to solve contradictions between institutionally defined tasks and the ambition of patient involvement.
\end{abstract} als who welcomed me, let me listen to their talks with patients, and told me about their practice. An equally big thank you to the cardiac patients who told me about their lives and experiences of contracting heart disease and allowed me to join them along their care pathways. I would also like to thank Betina Dybbroe for valuable comments on drafts of the article.

Conflict of interest: The author declares no conflict of interest.

Funding statement: The article is based on the PhD study conducted by the author, which was carried out with joint funding from Roskilde University and the Danish region mentioned in the article. The Danish region in question is anonymized in the article to maintain the anonymity of the hospital ward where the fieldwork was conducted.

Availability of data and materials: All documents analysed are publicly available. Local instructions from the hospital are publicly available as well; I have not provided the link to these, as I wish to maintain the anonymity of the hospital ward.

Ethics approval and consent to participate: The study was registered and approved by the Danish Data Protection Agency. Relevant permission to conduct fieldwork was obtained from the hospital management and from involved health professionals and patients. All participants are anonymised. The patients participating in the study have all been informed orally and in writing and gave their consent.

Received for publication: 12 November 2020.

Accepted for publication: 1 April 2021.

This work is licensed under a Creative Commons Attribution NonCommercial 4.0 License (CC BY-NC 4.0).

${ }^{\circ}$ Copyright: the Author(s), 2021

Licensee PAGEPress, Italy

Qualitative Research in Medicine \& Healthcare 2021; 5:9489

doi:10.4081/qrmh.2021.9489

\section{Introduction}

Patient involvement has increasingly become part of the way European healthcare systems seek to organise and produce healthcare services..$^{1-3}$ In Denmark, patient involvement is considered relatively well-developed at the formal level; patients have extensive rights to choose providers and to voice opinions about services. ${ }^{3,4}$

The literature has seen a rapid increase in studies of involvement and related concepts such as empowerment and patient-centred care. In different constellations, patient involvement is seen as a means to improve healthcare, provide more equal, less hierarchical clinicianpatient relationships, and increase patient influence. The patient is perceived as having progressed from being a passive service recipient. Instead, patients are considered resourceful and active individuals who can take responsibility for self-care. ${ }^{3,5,6}$

Patient involvement covers various understandings and practices. ${ }^{2,7,8}$ Scholars have generally pointed out a lack of clarity in the definition and purpose of patient involvement. ${ }^{7,9,10}$

Conceptually, models and frameworks have been developed that define different types of involvement. ${ }^{1,11,12}$ In the Nordic countries, in key health policy documents and reports, various involvement discourses have been identified. ${ }^{13,14}$ While these analyses contribute important knowledge about involvement at the policy level and provide tools to elucidate the lack of theoretical clarity, they 
reveal little about how involvement is manifest in specific practice contexts.

This article deals with involvement at a local and contextual level in a hospital ward in Denmark. By analysing data from more comprehensive ethnographic fieldwork, the article aims to produce micro-sociological insights into how involvement is constituted in actual activities, and how it is institutionally conditioned and shaped.

Empirical studies of involvement are often based on specific definitions or models of involvement to which practices are then related; the conclusions then reveal the discrepancies between ideal and practice. ${ }^{15-17}$ This study employs a different approach. Methodologically and analytically, the article draws inspiration from D. E. Smith's institutional ethnography (IE). This implies an inductive approach where discovery is central; the research process does not start from predefined theoretical understandings or concepts. Instead, people's experiences set the problematic of the study. ${ }^{18}$

My point of departure for studying involvement with this approach is an episode from my initial fieldwork: I was conducting a pilot study, which involved accompanying various clinicians in outpatient rehabilitation of cardiology patients, and I was observing a doctor's consultation with a 77-year-old woman. The woman had not participated in the physical exercise that was part of the rehabilitation program, and when asked for her reason for this, she explained that it was due to influenza and lack of energy. During their conversation, the doctor repeatedly recommended exercise, emphasised the importance of this and informed her of her options: she could either exercise in the outpatient program at the hospital or enter a municipal exercise program. She expressed her preference for the outpatient program, but maintained that she wanted to wait until she felt better.

The conversation could be analysed as an example of shared decision-making, an involvement model that has received particular attention in Danish healthcare. The idea is to facilitate a partnership between patient and clinician, where mutual exchange of knowledge and information forms the basis for decision-making. However, when the woman had left the room the doctor turned to me with these words:

I make a big point of telling her how important exercise is, but she still doesn't do it.... How can you involve someone like her?? She says she has no extra energy. How can I persuade her to do what's good for her??

What struck me about this is that she was not recognised as a patient who made informed decisions, but instead, was articulated as representing a failed attempt at patient involvement. This posed a problem to me: How does he actually understand involvement? What should I consider as involvement if this was not a case of it?
In IE, the researcher tries to discover and unpack what specific actions are concealed in the use of abstract and taken-for-granted words (such as involvement). It is not assumed that involvement exists (or should exist) as the same phenomenon across contexts; instead, the researcher makes it an empirical issue to reveal precisely how it exists. ${ }^{19}$ The focus is on exploring how practices (specific activities, actions, and interactions) are structured by objectified, extra-local forms of social organisation, which IE terms "ruling relations." Ruling relations are constituted externally to the local particularity of people and places and are mainly textually mediated. Texts such as policy documents and guidelines are read and taken up in specific practices; they thus regulate chains of action across local contexts and make actors and actions institutionally recognizable. The aim of this article is thus not to conduct a policy analysis, but to analyse how policies and other texts are activated in practice, affecting the ways in which involvement can manifest itself in specific local activities and interactions in cardiac rehabilitation, as well as how involvement is woven into and shaped by certain logics from practice.

\section{Patient involvement in Danish cardiac care}

In Danish healthcare, we see an ever-increasing focus on patient involvement. Historically, the right to informed consent became a legal requirement in 1992; patients must be informed of the possibilities and risks of treatment and consent to treatment before it begins. The Health Act guarantees all inhabitants of Denmark the right to treatment, free choice of hospital, guaranteed waiting times, and involvement in treatment decisions. Systematic involvement of patients is part of the national quality assurance program, where hospitals are regularly accredited based on various general objectives. Danish regional healthcare also includes patient involvement in its quality, patient, and communication policies. An involvement model that has received particular attention in Danish healthcare is shared decision-making, ${ }^{8,15}$ and in 2016, the government allocated DKK 38 million for the development of tools to support shared decision-making with a view to introducing these in many areas of healthcare, including cardiology.

In cardiology, patient involvement was placed on the agenda following the DANREHAB trial, ${ }^{20}$ while the report Cardiac Rehabilitation: A Medical Technology Evaluation, Evidence from the Literature and the DANREHAB Trial $^{21}$ emphasised that the basis for successful rehabilitation is patient involvement.

Patient involvement is important in cardiology because heart patients often have difficulty in maintaining long-term lifestyle changes. ${ }^{22}$ They also have complex, non-linear recovery processes and individually unique ways of dealing with heart disease. ${ }^{23-25}$ Positive effects of patient involvement include perceived greater ownership 
and responsibility for the care process and higher treatment satisfaction. ${ }^{15,21,26}$

When cardiac care pathways were introduced in 2010, patient involvement was formally included in official recommendations. Patient pathways apply to the entire care process (from suspicion of disease to treatment, rehabilitation, follow-up care, and monitoring) and are used across sectors, units and professional groups. They are part of a more general transformation in Nordic healthcare services towards increasing standardisation with the aim of creating uniform services and levels of quality, while also reducing costs. The general move towards standardisation has been criticised for upsetting the balance between humanistic and medical aspects of practice, and the concept of patient pathways has been highlighted as a policy-driven transformation that challenges rather than increases quality of care. ${ }^{27,28}$ Concerning cardiac care, the Danish Health Authority states that pathways aim to create a more uniform, consistent process, shorter waiting times, and a more appropriate prioritisation of resources. ${ }^{29}$ This suggests an ambition to make pathways more efficient, but also more reliable through increased formal interdisciplinary collaboration and coordination. In the context of the cardiac pathways, patient involvement is included as a means of enhancing consistency and continuity.

In the following, I outline the analytical approach and the empirical material that analysis draws on which consists of observations from a hospital ward and some of the key policy documents in cardiac rehabilitation in Denmark. I will then proceed to analyse how these texts regulate local practice and discus the implications of this in relation to patient involvement.

\section{An institutional ethnographic approach}

Methodologically and analytically, this article is inspired by IE. One such inspiration is to examine "people's actual doings" (p. 55). ${ }^{18}$ instead of assuming that a phenomenon (such as involvement) exists in the same form across different contexts. In IE, the researcher tries to unpack what practices are concealed in the abstract and taken-for-granted use of nominalizations. Nominalizations, such as involvement, are terms that convert verb forms into nominal forms thereby rendering invisible the specific subjects and their activities, ignoring that "someone or something does something or is supposed to do something" (p. 111).$^{18}$ The idea is to invert the procedure and reinstate people and their activities. In my context, this means that I focus on involvement as a process where someone must involve somebody in something, and I concentrate on the specific local events, i.e. the rehabilitation activities, which both patients and healthcare professionals are a part of.

Although IE focuses on the empirical description of local activities, it is equally important to explore how these activities are linked to objectified extra-local ruling relations. Ruling relations denote trans-local forms of social organisation and social relations that are objectified in the sense that they are constituted externally to the local particularity of people and places. ${ }^{18} \mathrm{~A}$ key point for Smith is that people's actual doings are coordinated by ruling relations, which are mainly textually mediated. Texts can be read and adopted across local contexts and can therefore regulate and standardise people's activities independently of time, place and person; people's actions become recognizable as institutional activities. ${ }^{19}$ According to Smith, texts must be considered as something that happens. They enter and are activated in specific situations, where they organise and regulate actions, consciousness, and subjectivity. Texts are activated when they are read, watched or heard. The readers engage in "text-reader conversations" (p. 174), described by Smith as the consciousness being brought into an active relationship with intentions originating beyond the local. ${ }^{19}$ "Its activation by a reader inserts the text's message into the local setting and the sequence of action into which it is read" (p.105). ${ }^{18}$ Unlike face-to-face conversations, text-reader conversations are characterized by the one side of the conversation being fixed and unresponsive. The other side of the conversation - the reader - is active in responding to, interpreting and acting from (interpretations of) the text. ${ }^{18}$ The text, however, remains a constant point of reference against which particular interpretations can be checked, and in this constancy, lies the standardising effect. ${ }^{19}$ However, it is important to note that they do not determine actions, but rather regulate and shape institutional actions in similar ways across local contexts. ${ }^{19}$ Exactly how specific texts happen must be discovered in the local context. ${ }^{19}$ The IE perspective thus captures the particular and the extra-local at the same time.

While centring on specific subjects and their actual activities, an IE perspective views subjectivity and agency as being constituted in texts through institutionally defined properties and categories: "subjectivity...organised as objectives to be pursued, tasks to be undertaken, [and]others to be connected with.... Such organisational/ institutional categories locate subjects in procedures, processes, tasks, and so on that are standardised in authorised texts" (p. 185). ${ }^{19}$ The subject of analysis is thus not the individual, but rather how subjectivity is organised and how institutional procedures localise subjects as actors. Consequently, this article focuses on clinicians and patients as actors and their institutionally orchestrated actions and interactions.

\section{Empirical material}

This article is primarily based on empirical material from observations in a cardiology ward. These observations were part of a larger longitudinal ethnographic study, which followed five heart patients from discharge, throughout their rehabilitation and continued subsequent to the termi- 
nation of the outpatient program up until one year after their heart incident. (See the Appendix for a more detailed description of the full research design.) The empirical material consists of field notes and transcribed recordings of clinician-patient dialogues both from a preliminary pilot study and the main study in which I attended various outpatient rehabilitation activities including patient education sessions, individual consultations with doctors, nurses, dietitians, psychologists and physiotherapists, and an eight-week physical training program.

The ward was selected as an example of a hospital ward in a Danish region with patient involvement as an objective. Relevant permission was obtained from the hospital management. The names of patients in this article have been replaced by pseudonyms. All were informed about the study orally and in writing, gave their consent. The referred dialogues with healthcare professionals were informal and are all anonymised. The study was registered and approved by the Danish Data Protection Agency.

During the fieldwork period, preliminary observations were presented and commented on by a reference group consisting of clinicians from the cardiology ward. Excerpts from the data and draft analyses were also presented and discussed with other PhD students at interpretation and analysis workshops at Roskilde University.

Analyses also draw on data from key policy documents and local instructions, as I will now proceed to elaborate further on below.

\section{Selection and description of active texts}

In a complex institution like a hospital, many texts will naturally be activated in daily practice, and they could not all be examined in this study. In my analysis of rehabilitation activities, I include certain texts as particularly important and active. The texts were selected after the process of conducting fieldwork was terminated and during the process of analysis.

The first is the description ${ }^{\mathrm{i}}$ of Patient Care Pathway for Unstable Angina Pectoris (UAP) and Acute Myocardial Infarction without ST Elevation (NSTEMI), ${ }^{29}$ which has a coordinating function in pathways that cross sectors, units, and professional groups. Each step in the pathway from suspicion of heart disease to treatment and rehabilitation is described, including procedures, timings, clinical actions and decisions, logistical actions, administrative procedure codes, information for patients,

\footnotetext{
In 2017, the Danish Health Authority decided to phase out the cardiac care pathways described in their form at the time. The reasons were that the procedures were too inflexible and difficult to use in everyday clinical practice and particularly, that the stipulated periods for various actions made little sense to patients and professionals. The pathways were replaced by a series of recommendations based on their content. The professional basis thus remains unchanged, while the fixed periods and requirements for additional registration in the pathway description are no longer valid.
}

and which actors are involved and responsible for the various steps.

This is the only text discussed with an explicit focus on patient involvement, and I therefore devote some space to how involvement emerges here.

As mentioned, patient pathways aim to create more consistency and continuity in patient care. Consistency and continuity refer to the coordination of activities between different sectors, units and healthcare professionals involved in the patient pathway in order to minimise unnecessary waiting time. ${ }^{29} \mathrm{It}$ is also emphasised that no patient should feel left alone without involvement, clear information, and scheduled appointments. ${ }^{29}$ In the pathway description, patient involvement implies ensuring that the patient has an overview of the pathway, which appears to mean informing the patient about the treatment and pathway: "As part of the communication, patients and their relatives must be continuously involved and informed about results of examinations and the next stage of the pathway" (p. 10). ${ }^{29}$

The document does not actually define involvement, but links it to the legal requirement for informed consent. It states: "The legal requirement for informed consent must ensure that the patient is involved in all treatment decisions. The patient and the healthcare professional must jointly decide on the pathway, to which the patient must consent, after receiving complete information" (p. 10)..$^{29}$ This does not appear to suggest an understanding of involvement that goes beyond the requirement of informed consent. Further, all the specific decisions described for each stage of the pathway are defined as clinical and to be taken by the professionals.

Elsewhere, the wording suggests that involvement not only relates to information for patients, but also to their resources and needs, e.g.: "In addition to knowledge and understanding of the patient's individual communicative ability, patient involvement requires professionals to actively involve the resources and accommodate the needs of the patient and the patient's relatives" (p. 11). ${ }^{29}$

The document states that rehabilitation must be organised individually in consultation with the patient, but it must also be based on the pathway standard, "where the separate stages are organised as well-defined events in terms of timing and content and follow a pre-determined path" (p. 3). ${ }^{29}$ The patient is thus supposed to participate in planning the pathway, but there seems to be limited scope for this in a pathway that is pre-determined and standardised in terms of timing and content. Moreover, responsibility for assessing patient needs lies with the professionals. What must be assessed is whether the patient should be offered all or only parts of the pathway. There is thus no provision for the patient to be active as an actual decision-maker, and what the patient may accept or reject are activities in a standardised offer.

Apart from the above, there is no indication of the patient's role in the process. The only patient contribution 
mentioned is informed consent, and there is no further explanation of actively involving the patient's resources or of the patient needs to be met.

The second text is the National Clinical Guideline for Cardiac Rehabilitation ${ }^{30}$ which describes recommendations and best practice for rehabilitation and its elements. The document provides evidence for these elements, which include both specific activities and the content of the program, such as physical exercise, patient education, psychosocial care, detection of anxiety and depression, dietary interventions, and smoking cessation. Further, it provides instructions for how to systematically refer to the pathway, handle barriers to adherence, and examine patients' employment situation.

The document is targeted at healthcare professionals and "can be used by professionals in decision-making about appropriate and sound clinical care in specific situations" (p. 8). ${ }^{30}$ The guidelines are not legally binding, but the Danish Health Authority recommends following them, and decisions that deviate from the recommendations must be justified. In addition, the regular accreditations involve an assessment of whether the recommendations have been followed. ${ }^{30}$

The final type of text is regional or hospital-based instructions for healthcare professionals. I was referred to these documents by healthcare professionals during the fieldwork. These are specific guidelines for each rehabilitation activity, describing the purpose, procedure, responsibility and documentation of the activity. These instructions can be seen as an intertextual complex: each instruction refers to other instructions that elaborate on various topics and areas of rehabilitation. For example, instructions for talks with individual patients describing topics to be reviewed can refer to other instructions in relation to the specific procedure for obtaining and providing information within the defined topics. All the instructions point out that the staff in the cardiology ward is responsible for knowing and following them.

The selected texts have been included for various reasons: i) They all contain declarations on clinicians' responsibility to know and follow the instructions, which means that clinicians are actually obliged to engage in text-reader conversations with these documents; ii) They all provide instructions on the content and procedures of the process that can be recognized in the organization of the actual rehabilitation activities and interactions, as the analysis will show. However, it should be noted that these documents do not actually contain anything about patient involvement, except for the pathway description, as described above.

I will now proceed to analyse how the selected texts happen and are active in the interactions and activities of the local rehabilitation program. The first two sections focus primarily, but not exclusively, on how notions from the national documents (the pathway description and the National Clinical Guideline) unfold in practice. The last section will dedicate more attention to the regional and local instructions. This, however, is an analytical distinction. As analysis will show, several texts can be said to be at work simultaneously in specific interactions.

\section{Rehabilitation as a bridge}

The description of the pathway divides it into three phases, where Phase I is treatment, and Phase II is outpatient rehabilitation (the subject of this article); this includes optimisation of medical treatment, patient education, physical exercise, support for dietary change, smoking cessation, psychosocial support, clinical monitoring, and follow-up care. Phase III concerns the maintenance of preventative treatment and of achieved lifestyle changes. Rehabilitation is thus a process that extends beyond outpatient care and into patients' everyday lives. The division into phases has organising capacities in the sense that it creates a general narrative of linear progress (treatment $\rightarrow$ changing lifestyle $\rightarrow$ maintaining achieved lifestyle changes) that can be rediscovered in the actual interactions between patients and healthcare professionals. In specific pathways, it is taken up by the professionals, e.g., when rehabilitation is described as a bridge or a transition and patients must continue themselves: "This programme is time-limited. Afterwards, you should continue yourself. You continue with this lifestyle change" (patient-physiotherapist dialogue, September 2015). "You exercise with us as a bridge to making progress yourself "(doctor-patient dialogue, June 2015). In this way, Phase II is interpreted as an intermediate station, before patients become capable of making progress themselves and assume responsibility for the preventative measures. This locates the patient, as an institutional category, in a transformative process of becoming responsible and capable of certain actions. It also carries the assumption that patients are not responsible or capable of making progress themselves when they initiate the program. The means of achieving this transformed patient becomes visible when we look closer at the actual activities and interactions in relation to the National Clinical Guideline. This text is important because it names, describes, and recommends the activities that a rehabilitation program should consist of e.g., physical exercise, dietary interventions, etc.

The recommendation of patient education is particularly interesting because it enters practice in ways that are not confined to formal group teaching sessions. It seems to be at work in several other activities as well such as individual consultations and physical exercise. For example, physiotherapists teach patients about the different effects of interval exercise and strength training and of how to measure their level of physical exertion by the Borg-scale.

The National Clinical Guideline states that the aim of patient education is to "strengthen patients' self-care, capacity for action and autonomy and give them an understanding of the disease and its treatment" (p. 21). ${ }^{30}$ 
It recommends a combination of group teaching and individual counselling and lists the relevant general topics. In practice, group teaching focuses on general knowledge about the heart, heart disease and related topics (such as symptom recognition, medication, side effects, diet, mental reactions, exercise, legislation), which is in line with the recommendation. Individual consultations cover the same topics as group teaching, but are more individualised, e.g., participants are told what was wrong with their heart in particular, and individual lifestyle adjustments are discussed based on diet, smoking, alcohol, and exercise (four key factors in Denmark) and on the participant's blood test results.

The focus on knowledge to enhance patients' own capacity for action from the National Clinical Guideline, is taken up by healthcare professionals in the group teaching sessions where patients are told: "This teaches you to take care of your condition yourself." (doctor teaching about medication and side effects, July 2015) and "If you can understand what's wrong, you can also understand what to do" (doctor giving introductory lesson, June 2015).

In individual consultations, the educational aim is seen in the way patients are often asked to repeat what they remember from the teaching, e.g. about diet: "What are the good fats?" "What types of meat are heart-friendly?" "How many hours of exercise per week does the Danish Health Authority recommend?" The focus is on patients' (missing) knowledge, on making them understand, and on promoting compliant behaviour. One doctor told me that he tried to form an impression of whether they "had got the message," whether they "would comply in the future," whether he "could send them home with a clear conscience," and whether "they take responsibility for their lives" (conversation with a doctor, June 2015).

As mentioned previously, the National Clinical Guideline lists the general teaching topics. It also states that "the content must be based on topics that are important to patients and relatives to know more about. The general topics will be: the normal and the sick heart symptoms, medication, diet and intake of fluids [etc.]" (p. 25). ${ }^{30}$ One could ask how it can be predefined in a policy document what will be important to patients if they are understood as actual and specific individuals. Instead, here they are an institutional category characterised by a lack of certain knowledge. What is important to them is defined externally, from a place (the text) outside their own experience.

In the local context of the rehabilitation program, the healthcare professionals solve this schism by trying to adapt information to patients based on their diagnosis and treatment and on an impression of what they already know. For example, during group teaching, the dietitian starts the lesson by asking them, in turn, what they consider heart-healthy food. They then mention low-fat food, vegetables, fish, etc. The dietitian then says, "You've grasped the essentials, but I didn't hear you mention bread that much." She talks about wholemeal bread and shows a power point slide with a diagram of foods divided into categories: green (food you basically cannot have enough of), yellow (food you can replace with something else) and red (food you really should cut down on) (Lesson by a dietician, June 2015).

It is thus a question of sorting and prioritising information and topics already determined: what patients must know to perform self-care in accordance with the evidence in the National Clinical Guideline.

Regarding individual consultations, a nurse told me that she uses the patient's narrative as a basis for choosing relevant topics from among those defined in the local instruction. She explained that she uses the instruction as a checklist during conversations. In this way, the text enters the actual interactions. The nurse engages in a text-reader conversation interpreting the local instructions and the patient's narrative in relation to each other thereby assessing what are the most important themes from the instruction in the case of this particular patient.

Further, the nurse told me that patients often "need knowledge about their particular illness and its development." She explained to me that she often starts the conversation by getting them to talk about their illness experience and pathway and that this gives her an insight into how they have experienced their disease and what is important to them: "What they have understood out of everything they have been told. You cannot remember it all. They often need to know what exactly was wrong in their particular case, and what has been done" (Conversation with nurse, August 2015).

This suggests that the aim of the dialogue is not just to discover what is important to the patient in his or her own experience, but also to find out what the patient has understood. In other words, she is performing the task of identifying knowledge gaps, which can be seen as the activation of the educational scope in the National Clinical Guideline.

So far, I have pointed out how different texts play a structuring part in the actual activities and interactions in the local context of the rehabilitation program. The pathway description organizes patient pathways in a general narrative of progress that places patients in a transformative process of becoming capable of taking responsibility for preventive measures themselves. This is to be achieved by educating the patient (based on the recommendations in the National Clinical Guideline), providing them with health knowledge that is deemed important independently of the individual patient. In these documents, the patient as an institutional category is characterized by a lack of knowledge. The notion of educating the patient can be seen as a ruling relation as it originates beyond the local context of the rehabilitation program, but structures the actual interactions between healthcare professionals and patients. It organises consciousness and actions as it orients healthcare professionals to the task of identifying 
knowledge gaps in order to select information relevant to the actual patients in individual consultations as well as group teaching sessions.

\section{Imperative and assumed decisions in cardiac rehabilitation}

In this section, I will address some of the implications of the previously mentioned narrative of progress in relation to actual dialogues drawn from two consultations. The narrative of progress was identified in the way the pathway description divides the pathway into phases and in healthcare professionals' conceptualisation of the rehabilitation program as a bridge.

The narrative implies the assumption that patients in rehabilitation make lifestyle changes in the areas mentioned, that in Phase III there are some achieved lifestyle changes that can be maintained. This presupposes patients who actually decide to change their life and succeed in this. The opposite scenario (that a patient does not make lifestyle changes or tries but fails) is not addressed in the text and thus does not seem to be an alternative that healthcare professionals can operate with. One professional told me during the fieldwork that patient involvement in decisions only seems relevant to a limited extent, as patients have already completed their treatment (i.e., specific interventions such as balloon dilation or bypass surgery). Rehabilitation is thus understood as a kind of follow-up process when the decisions have already been made.

In consultations with patients, healthcare professionals regularly assume that they have decided to make lifestyle changes. Dialogues focus on which types of exercise the patient prefers and which dietary adjustments can be made. Thus, the relevant decision is a question of which ones, while the decision to actually make lifestyle changes is a given. In Christine's case, for example, the nurse advises her to find a type of exercise that she feels like doing, since she does not like exercising in the gym. After talking about diet and blood tests, the nurse returns to the subject of exercise, telling Christine that in, addition to improving her glucose levels, exercise does her a lot of good:

Nurse: You avoid lots of diseases. It's healthy in many ways, she adds.

Christine: Yes, I know that.

Nurse: I can explain it on a lower level. [She takes a model of an artery and begins to explain.] If the blood clot has been in any of the small arteries around the heart, they can't always find it.

This is likely in Christine's case, she explains, because they can see that there has been a blood clot, but have not found it. She explains how fatty deposits can occur, causing inflammation which can make the artery rupture more easily. Exercise, the nurse continues, stabilises and prevents the arteries from rupturing so easily. Exercise and a heart-friendly diet including vegetables and fibre, slow down the inflammatory process:

Nurse: What do you think about that?

Christine: Well, yes, I must try that.

The nurse says that sitting still and smoking is almost as risky.

Christine: Yes, I do that. There's no reason to lie about it.

The nurse continues by saying that it will be great if Christine can integrate exercise:

Nurse: You don't want to come back here in five years. I'm sure you want to keep going for many more years.

Christine: You're very nice, but I think I can find a better way to spend five days than

coming here.

Nurse: Alcohol? Do you drink alcohol?" (dialogue between Christine and a nurse,

March 2016)

Integration of exercise in Christine's life appears here to be a matter of life and death; if she refuses to exercise, she is choosing death within five years. The fact that the choice to make lifestyle changes is not understood as a real choice can be seen as an extension of the close relationship between heart disease and lifestyle, implying that an unchanged lifestyle almost equates with the choice of a new blood clot. In this way, the decision to integrate exercise in her everyday life appears imperative.

It is interesting to note how multiple texts seem to be at work in this interaction: i) the imperative to change lifestyle from the pathway description, ii) the nurse's explanation of "what happens inside the artery" in line with the educational aim from the National Clinical Guideline, and iii) the sudden jump from one subject (exercise) of conversation to another (alcohol). This change of subject is not prompted by anything in the actual exchange but derives from somewhere outside the conversation, more specifically from the local instruction of nurse consultations that specifies the topics to be touched upon in this type of conversation. As a result, the instruction regulates the interaction in a way that makes the conversation resemble an interview more than an actual dialogue.

Returning to the subject of imperative decisions in the rehabilitation program, the following dialogue between Ejner and a nurse, is an example of a consultation in which the decision to make lifestyle changes is challenged:

Nurse: So if you make a mental note of it, that everything from the animal kingdom is bad, except fish, and everything from plants is good. 
Ejner: That's funny. All that healthy stuff. It's usually more expensive. Let's say fish, for example. If I buy salmon for myself, that's a hundred kroner, but you can buy mincemeat that costs twenty. Then hell, I'd rather buy the mince.

Nurse: Yes, well that's-

Ejner: Because you don't get so much on a state pension.

Nurse: No, but once again-

Ejner: Just occasionally, of course.

Nurse: It's up to you. I can only inform you about what we recommend from here. Of course, we know from many years of research that this is how we recommend you to live if you want to avoid getting ill again or your atherosclerosis getting worse. But, of course, I can't, I can't tell you to do it, you know. You choose yourself when you're out shopping, what you want." (Dialogue between Ejner and nurse, June 2016)

Ejner's objection is that, as a state pensioner, he also has to think of his finances, and he cannot afford to buy fish twice per week. However, the nurse does not seem to recognise his small state pension as a real problem, but instead speaks of it as a choice. Moreover, there is clearly a right choice, supported by many years of research. She cannot force him, but if he makes the wrong choice he risks getting ill again or getting a narrowing of the arteries in his heart, and he chooses himself when he's out shopping. In this way, Ejner's decision seems illegitimate, as it challenges the recommendations for a heart-healthy diet. This episode demonstrates what can happen when healthcare professionals encounter patients who do not fit in with the pathway description's notion of a patient that during Phase II makes the appropriate lifestyle changes. Ejner basically just ends up being held accountable for his "choice." The exchange does not lead to any real help or solution for him, nor any real recognition of his situation.

This section has pointed out how the general narrative of progress in the pathway description assumes the decision to make lifestyle changes. This assumption organizes the actual interactions in the way that it directs focus to the question of which ones, while the decision to change lifestyle in the designated areas appears imperative. When the assumption is challenged, the patient is assigned with the responsibility for the recurrence of the disease.

\section{The ruling relations of individual consultations with healthcare professionals}

In the following, I will use the two examples of consultations above to discuss what makes the dialogues develop in this particular way. How can it be that the nurse responds to Ejner's objections by holding him accountable for his choices? Why are patients faced with the re- currence of their disease, followed by death, if they do not follow the recommendations? These actions do not appear to originate from interpretations of the pathway description. As indicated, it does not operate with the concept of a non-compliant patient.

During the fieldwork, one nurse called it a "dilemma" for clinicians when patients' wishes run contrary to professional recommendations

because it looks bad if we don't get the patient to achieve our goals.... It's difficult, because you're trained so much in guidelines that you have to follow, and you're kind of a bad nurse if you can't get a patient to stop smoking (conversation with nurse, June 2016).

On the one hand, healthcare professionals are asked by management to involve patients, but on the other hand, they must follow guidelines and instructions that give them tasks that do not necessarily harmonise with the ambition of patient involvement.

Previously, we saw how instructions constrained the dialogues between nurses and individual patients. In addition, the goals the nurse mentions above are institutional goals, which must be given priority in consultations with patients because the hospital's performance is measured by these. The nurses I talked to said that these goals are satisfactory blood pressure and cholesterol levels, the correct amount of exercise according to the recommendations, and smoking cessation. In addition, part of the ward budget is withheld and only paid out if the set goals for blood-thinning treatment and screening for diabetes have been achieved. There are thus several "layers" of ruling relations, such as the limiting of topics in the instructions and the financial sanctions linked to certain mandatory elements in every dialogue. According to the nurses, this means more focus on what can be measured than on other things. As one of them stated, there are "many things to do, so it's a bit easier to make sure the blood pressure is ok than 'How can I actually involve this patient?" (conversation with a nurse, June 2016).

In Ejner's case, the subject of the interaction is diet. The instructions describe this as a risk factor, i.e. one of the subjects to be discussed with the patient (Local instructions on Cardiac Rehabilitation - Individual, and Cardiac Rehabilitation - Nursing). The general instructions for patient interviews specify that i) patients must be "screened for health risks" by asking about their current lifestyle, and ii) the "health risks must be assessed" by comparing the screening result with the recommendations of the Danish Health Authority and the patient's illness, and iii) "if the patient has an unhealthy lifestyle, there must be an intervention" in the form of information about present and future health risks (Local instruction on Health Risks - Identification and Intervention).

These instructions combined indicate an institutional 
procedure in which certain actions (screen, assess, inform) must be performed by the institutional actor (here the nurse). It is also specified how these actions are to be performed: patients must be questioned, results must be compared with the recommendations, patients must be informed about risks, all of which is essentially what the nurses do in the dialogues above. The instructions thus clearly define and structure the nurse's focus and actions as an institutional actor, and the standard of the recommendations becomes the framework for defining the patient's problems. The instructions contain nothing that could support advice based on the patient's actual situation; furthermore, the responsibility for assessing patient needs lies with the professional.

This assessment takes the form of a standard procedure, which is also described in the instructions. For example, regarding diet, instructions state: "Patients who, based on the Health Authority screening form for eating habits, have four negative responses, have very unhealthy eating habits and therefore need advice/an intervention." Regarding exercise: "Patients who, based on the Health Authority screening form for physical activity in leisure time, place themselves in category 1 , are at risk of developing illness due to lack of physical activity, and therefore need advice/an intervention." (Local instruction on Health Risks - Identification and Intervention, emphasis added). The patient's needs are thus defined externally to the patient and can be clarified and assessed by the clinician through the established institutional procedures. Agency is textually constituted by means of the nominalizations advice and intervention. In the local actualities, these are actions: someone must advice and intervene. The text allocates agency to the healthcare professionals. Patients, on the other hand, are assigned with needs, but not with the agency of making their own assessments of these needs. Patients are thus textually constituted as passive entities, as objects of interventions in an institutional procedure that overrides their subjective experiences and perspectives.

\section{Discussion and Conclusions}

Analysis presented above has provided insight into how patient involvement is shaped in local rehabilitation practices. Here, patients are predominantly seen as recipients of knowledge, at a more general level in the group teaching and at an individual level in consultations. Roughly speaking, one could say that the professionals' task is to involve the patient in health knowledge. The requirement for healthcare professionals to be able to send patients on to Phase III with a clear conscience, as expressed by the doctor above, is that patients gain understanding and act in compliant ways. In this light, the doctor's questions from the beginning of this article start to make sense. The 77-year-old woman has not understood the importance of exercise, despite the doctor's attempts to explain it. She refuses to participate and can therefore not be involved in the knowledge that will give her a heart-healthy lifestyle.

In line with other studies, the analysis has also shown that decisions on lifestyle changes are assumed and that patient preferences become illegitimate and conflictual when they deviate from health recommendations..$^{15,17,31}$ Part of the explanation is that the documents that structure the pathway (the textually mediated ruling relations) presuppose patients who are willing to make, and succeed in making, the recommended lifestyle changes. They presuppose that there are some lifestyle changes that the patient can maintain in Phase III of rehabilitation. Furthermore, the dialogues are structured by the healthcare professionals' instructions in ways that guide the professionals' focus towards identifying knowledge gaps and risk factors which frame the definition of the patient's problems. This focus shifts attention away from the patient's perspectives and life situation, just as the instructions constrain the dialogue. The textually mediated ruling relations structure the agenda, actions and interactions, and consequently, patient involvement is shaped in ways that do not suggest more influence for the patientsuch as influence on the agenda, topics to be discussed, and the patient's own definitions of needs, problems or solutions.

However, the clinicians' statements also seem to contain other understandings of patient involvement than providing the patient with health knowledge. Different professionals probably have diverse approaches to patient involvement; studies show a wide range of understandings of patient involvement within and across professional groups. ${ }^{26,32}$

The point, however, is that there is little in the institutional documents to support other approaches to patient involvement. The pathway description is the only document that explicitly mentions it, but this is done in nonspecific terms, without any clarification of the patient's actual role or contribution. Involvement of patients (if we understand involvement as not merely introducing patients to health knowledge) thus becomes a task for healthcare professionals to perform in addition to- perhaps even in spite of -guidelines, instructions and mandatory goals and based on their individual interpretations of what "involvement" means. Furthermore, it will be up to the individual healthcare professional to find ways to eliminate contradictions in this situation, which the nurse called a "dilemma." It is therefore by no means obvious how the involvement of specific patients in cardiac rehabilitation could take place.

Time, culture, and healthcare professionals' attitudes to patient involvement, along with (un)willingness to relinquish control, power, and authority, are often highlighted as facilitators or barriers to patient involvement. ${ }^{26,31-35}$ The findings of the present article add institutional texts, in their structuring and authorisation of institutional procedures and tasks, as a significant factor in local practice. As the analysis shows, institutional texts structure healthcare professionals' focus and actions as in- 
stitutional actors. For example, the professionals are to assess patient needs, and both what and how are described in the documents. It is thus not merely a question of willingness or unwillingness. Asymmetry and authority are inscribed in the documents that guide practice, and healthcare professionals are held responsible for knowing and complying with these institutional texts.

\section{References}

1. Tritter JQ. Revolution or evolution: the challenges of conceptualizing patient and public involvement in a consumerist world. Health Expect 2009;12:275-87.

2. Barnes M, Cotterell P. From margin to mainstream. In: Barnes M, Cotterell P, eds. Critical perspectives on user involvement. Bristol: Policy Press; 2012: pp. xv-xxvi.

3. Dent M, Pahor M. Patient involvement in Europe: a comparative framework. J Health Organ Manag 2015;29:546-55.

4. Olejaz M, Juul Nielsen A, Rudkjøbing A, et al. Denmark: health system review. Health Syst Transit 2012;14:1-192.

5. Mead N, Bower P. Patient-centredness: a conceptual framework and review of the empirical literature. Soc Sci Med 2000;51:1087-110.

6. Fotaki M. Towards developing new partnerships in public services: users as consumers, citizens, and/or co-producers in health and social care in England and Sweden, Pub Admin 2011;89:933-55.

7. Mockford C, Staniszewska S, Griffiths F, Herron-Marx S. The impact of patient and public involvement on UK NHS health care: a systematic review. Int J Qual Health C 2012;24:28-38.

8. Vrangbæk K. Patient involvement in Danish health care. J Health Organ Manag 2015;29:611-24.

9. Bochel C, Bochel H, Somerville P, Worley C. Marginalized or enabled voices? 'User participation' in policy and practice. Soc Policy Society 2008;7:201-10.

10. Pluut B. Differences that matter: developing critical insights into discourses of patient-centeredness. Med Health Care Phil 2016;19:501-15.

11. Barnes M, Cotterell P. User involvement in services. In: Barnes M, Cotterell P, eds. Critical perspectives on user involvement. Bristol: Policy Press; 2012: pp. 73-77.

12. Ortiz Halabi I, Scholtes B, Voz B, et al. "Patient participation" and related concepts: a scoping review on their dimensional composition. Patient Edu Couns 2020;103:5-14.

13. Askheim OP, Christensen K, Fluge S, Guldvik I. User participation in Norwegian welfare context: an analysis of policy discourses. J Soc Policy 2017;46:583-601.

14. Christensen K, Pilling D. User participation policies in Norway and England: the case of older people and social care. J Soc Policy 2019;48:43-61.

15. Jacobsen CB, Pedersen VH, Albeck K. Patientinddragelse mellem ideal og virkelighed: En empirisk undersøgelse af fælles beslutningstagning og dagligdagens møder mellem patient og behandler [Patient involvement between ideal and reality: An empirical study of joint decision-making and everyday meetings between patient and therapist]. Sundhedsstyrelsen, Monitorering \& Medicinsk Teknologivurdering and Dansk Sundhedsinstitut. Medicinsk Teknologivurdering - puljeprojekter 2008;8.

16. Knudsen M, Højlund H. Grænser for inddragelse: en analyse af inddragelsesidealer og beslutningsprogrammer på genoptræningsområdet [Limits of involvement: an analysis of involvement ideals and decision-making programmes in rehabilitation]. In: Kjær P, Reff A, eds. Ledelse gennem patienten: nye styringsformer i sundhedsvæsenet [Management via the Patient: New forms of leadership in health care]. Copenhagen: Handelshøjskolens Forlag; 2010: pp. 75-99.

17. Hsieh E, Bruscella J, Zanin A, Kramer E. 'It's not like you need to live 10 or 20 years': challenges to patient-centered care in gynecologic oncologist-patient interactions. Qual Health Res 2016;26:1191-202.

18. Smith DE. Institutional Ethnography: A sociology for people. Lanham: Altamira Press. 2005.

19. Smith DE. Texts and the ontology of organizations and institutions. Studies Cults Orgs Socs 2001;7:159-98.

20. Zwisler AD, Shou L, Sørensen LV, eds. Hjerterehabilitering: Rationale, arbejdsmetode og erfaringer fra Bispebjerg Hospital [Cardiac Rehabilitation: Rationale, Working Methods and Experiences from Bispebjerg Hospital]. København: Hjerterehabiliteringen, Kardiologisk klinik Y, H:S Bispebjerg Hospital; 2003.

21. Danish Health Authority. Hjerterehabilitering: en medicinsk teknologivurdering, evidens fra litteraturen og DANREHABforsøget [Cardiac rehabilitation: a medical technology evaluation, evidence from the literature and the DANREHAB trial]. Medicinsk Teknologivurdering - puljeprojekter 2006;6. Available from: https://www.sst.dk/ /media/97BEC54E347 646C6BAFEB31426261575.ashx

22. Janssen V, De Gutht V, Van Exel H, Maes S. A self-regulation lifestyle program for post-cardiac rehabilitation patients has long term effect on exercise adherence, J Behav Med 2014;37:308-21.

23. Tolmie EP, Lindsay GM, Belcher PR. Coronary artery bypass graft operation: patients' experience of health and wellbeing over time, Eur J Cardiovasc Nur 2006; 5: 228-36

24. Rolley JX, Thompson DR. Cardiovascular disease: is it time to finally recognize it as a complex, chronic life-span illness? Eur J Cardiovasc Nur 2012;11:135-37.

25. Hansen TB. Organisational, economic and patient perspectives on exercise-based cardiac rehabilitation following heart valve surgery. PhD Dissertation. SDU University of Southern Denmark. 2016.

26. Knowledge Centre for Patient Involvement (ViBIS): Sundhedsprofessionelles forståelser af patientinddragelse - en kvalitativ undersøgelse [Healthcare professionals' understandings of patient involvement: a qualitative study]. 2013. https://danskepatienter.dk/files/media/Publikationer\%20-\%20Egne/B_ViBIS/A_Rapporter $\% 20$ og $\% 20$ unders $\% \mathrm{C} 3 \% \mathrm{~B} 8 \mathrm{gelser} /$ sundhedsproffesionelles_forstaaels e_kvalitativ.pdf

27. Kamp A, Dybbroe B. Struggles of Professionalism and Emotional Labour in Standardized Mental Health Care. NJWLS 2016;6:67-86.

28. Gripsrud BH, Ramvi E, Ribers B. Couldn't care less? A psychosocial analysis of contemporary cancer care policy as a case of borderline welfare, J Psychosoc Stud 2020;13:247-62.

29. Danish Health Authority. Pakkeforløb for ustabil angina pectoris (UAP) og akut myokardieinfarkt uden ST-elevation (NSTEMI) [Patient care pathway for unstable angina pectoris (UAP) and acute myocardial infarction without ST elevation (NSTEMI)]. 2013. https://docplayer.dk/7268127-Pakkeforloeb-for-ustabil-angina-pectoris-uap-og-akut-myokardieinfarkt.html 
30. Danish Health Authority. National klinisk retningslinje for hjerterehabilitering 2013 [National Clinical Guideline for Cardiac Rehabilitation 2013]. 2015. https://www.sst.dk/da/sundhed/kvalitet-og-retningslinjer/nationale-kliniske-retningslinjer /udgivelser/ /media/401919781C684EE9AAE544EB5E7684 7B.ashx

31. Arnetz JE, Winblad U, Arnetz BB, Höglund AT. Physicians' and nurses' perceptions of patient involvement in myocardial infarction care. Eur J Cardiovasc Nur 2008;7:113-20.

32. Knowledge Centre for Patient Involvement (ViBIS): Læger og sygeplejerskers forståelse af patientinddragelse - en spørgeskemaundersøgelse blandt ansatte på hospitaler [Doctors' and nurses' understandings of patient involvement: a questionnaire for hospital staff]. 2014. https://www.regioner. $\mathrm{dk} /$ media/10285/laeger-og-sygeplejerskers-forstaaelse-afpatientinddragelse.pdf

33. Légaré F, Ratté S, Gravel K, Graham ID. Barriers and facilitators to implementing shared decision-making in clinical practice: update of a systematic review of health professionals' perceptions. Patient Educ Couns 2008;73:526-35.

34. Angel S, Frederiksen KN. Challenges in achieving patient participation: a review of how patient participation is addressed in empirical studies. Int J Nurs Stud 2015;52: 1525-38.

35. Jønsson AR, Baker VH, Jacobsen CB, Pedersen LH. Brugerinddragelse: forhandlinger af autoritet, relation og viden [User involvement: negotiating authority, relations and knowledge]. Tidsskr Forsk Sygdom Samf 2015;22:5-17. 